Lemont, Illinois

\title{
REVISED RADIOCHEMICAL IODINE ANALYTICAL PROCEDURE
}

by

Elton H. Turk

\section{CHEMICAL ENGINEERING DIVISION}

July 1954

Operated by The University of Chicago under

Contract $W-31-109-e n g-38$ 


\section{DISCLAIMER}

This report was prepared as an account of work sponsored by an agency of the United States Government. Neither the United States Government nor any agency Thereof, nor any of their employees, makes any warranty, express or implied, or assumes any legal liability or responsibility for the accuracy, completeness, or usefulness of any information, apparatus, product, or process disclosed, or represents that its use would not infringe privately owned rights. Reference herein to any specific commercial product, process, or service by trade name, trademark, manufacturer, or otherwise does not necessarily constitute or imply its endorsement, recommendation, or favoring by the United States Government or any agency thereof. The views and opinions of authors expressed herein do not necessarily state or reflect those of the United States Government or any agency thereof. 


\section{DISCLAIMER}

Portions of this document may be illegible in electronic image products. Images are produced from the best available original document. 
REVISED RADIOCHEMICAL IODINE ANALYTICAL PROCEDURE

by

Elton H. Turk

\begin{abstract}
A revised radiochemical iodine analytical procedure has been developed which will separate iodine activities from other mixed fission activities with a decontamination of $10^{5}$ or more. Data are presented which establishes the precision of the method at $\$ 2.6$ per cent based on ten samples.

The revised procedure utilizes the volatility of iodine to separate it from the other fission products except ruthenium. Ruthenium is removed by several solvent extractions of the iodine using carbon tetrachloride.
\end{abstract}

A method for detecting ruthenium contamination in the radiochemical iodine samples is presented.

\title{
INTRODUCTION
}

The beta activity of routine radiochemical iodine samples prepared in our analytical laboratory according to the procedure described in $\mathrm{CN}$ 2815 has been observed occasionally to decay with a 60-70 day half-life. This activity has also been shown to have a $0.7 \mathrm{Mev}$. gamma activity as sociated with it. It thus seemed possible that there was fission product zirconium contamination in the iodine samples. This could occur since the iodine was isolated in the older method by a solvent extraction procedure; if the zixconium, instead of being ionic in character, is polymeric, it could extract somewhat into the organic phase or concentrate at the inter face in such a manner that a portion of it would end up in the final purified sample of iodine.

The modified procedure is presented in the appendix and is based on a distillation of iodine carrier and activities, followed by several solvent extractions of the iodine as elemental iodine using carbon tetrachloride as the solvent. The distillation step separates the iodine activities from essentially all the fission activities with the exception of ruthenium. It is separated from ruthenium by several carbon tetrachloride extractions of the iodine. 


\section{EXPERIMENTAL}

The precision of the revised radiochemical iodine procedure was measured using carrier-free tracer iodine -131 obtained from Oak Ridge National Laboratory. Ten synthetic radiochemical iodine samples were prepared from this tracer by adding the tracer and a standardized iodide carrier ( $13.5 \mathrm{mg}$. PdI/ $/ \mathrm{ml}$ ) in an aqueous solution and then isolating the carrier and tracer by the revised radiochemical iodine procedure. Ten samples analyzed 1476 counts with a standard deviation of 38 counts. The precision of the method based on the standard error of the ten samples is thus $\$ 2.6$ per cent.

To test the radiochemical purity of samples prepared according to the revised radiochemical iodine procedure two samples were prepared. One was prepared by adding tracer iodine -131 to mixed fission activities which had decayed for two years to allow the original iodine activities to decay out: this particular sample had $10^{5} \mathrm{cpm}$. of iodine tracer mixed with $7.6 \times 10^{8} \mathrm{cpm}$. of mixed fission activities. The second sample was fission lodine activities isolated from a portion of ample of uranium oxide which had been irradiated in the Argonne CP-3 reactor for 56 hours and allowed to decay 13 days before analysis; this sample had $10^{11} \mathrm{cpm} / \mathrm{ml}$. of mixed fission activities. The beta activities of these two isolated radiochemical iodine samples have been characterized by absorption in aluminum and by decay observations, using an Ampurex $100 \mathrm{C}$. halogen quenched G.M. tube; these data are presented in Figures 1,3 and 4 . In Figures 1 and 2 , data are presented for a sample of iodine tracer separated from an aqueous solution by the same procedure; these data give a reference curve for the data for the two samples of lodine separated from mixed fission activities.

The aluminum absorption curve data in Figure 1 has been normalized to permit comparison on one graph. The three curves show the same two components, a beta with a visual range of $210-220 \mathrm{mg} / \mathrm{cm}^{2}$ and a very hard component. The energy of the beta from range-energy relationship is $0.6 \mathrm{MeV}$. which agrees well with published data for the energy of the major beta radiation of iodine 131. The flat tail of the curve is produced by the $0.36 \mathrm{Mev}$. gamma emitted in coincidence with the $0.6 \mathrm{Mev}$. beta decay; the amount of this gamma activity found in these samples using the Ampurex $100 \mathrm{C}$. G.M. tube was insufficient to obtain a lead absorption curve of any significance to characterize the gamma ray energy.

The decay curves presented in Figures 2 and 3 follow a 8.14 d. halflife life for the first 5 to 7 half-lives at which time a long-lived component appears. This long-lived activity was looked for in the original tracer and not found; also, on submitting the sample in Figure 3 after 118 days of decay

IJ.M. Hollinder, I. Pulman, and G.T. Seaborg, Review of Modern Physics, 25, 547 (1.953). 
to further chemical treatment it was shown that this activity was partially lost $\left(15 \mathrm{cpm} . / \mathrm{ml}_{\text {. }}\right.$ ) being reduced to $2 \mathrm{cpm} . / \mathrm{ml}$. From these facts it was concluded that the long-lived component was a trace of contamination introduced during sample preparation. The observed data has been corrected for $5 \mathrm{cpm}$. of long-lived contamination in Figure 2 and $15 \mathrm{cpm}$. in Figure 3 and the corrected data plotted on the same graph: the corrected decay data follows the 8.14 d. half-life line reasonably well down to 1 cpm. above normal background.

The decay curve in Figure 4 for the iodine isolated from green mixed fission activities shows no deviation from a 8.14 d. half-life line for 13 halflives at which time the counting rate is only $7 \mathrm{cpm}$. above normal background. This sample appears to be radiochemically pure $(1 \mathrm{cpm}$. of long-lived activity per $4.5 \times 10^{4} \mathrm{cpm}$. in the original sample).

From the decay curves and aluminum absorption curves it is seen that by using the revised radiochemical lodine procedure the radioactive iodine sample can be prepared radiochemically pure from samples containing from $10^{5}$ to $10^{6}$ times as much mixed fission activities as iodine activity.

If the radiochemical purity of the final sample prepared by this procedure is not enough, the sample could be carried through the same procedure a second time. By using new glassware the second time, the small amount of contamination introduced apparently by handling could be reduced to a point where it would be insignificant. For routine laboratory operation the procedure as described in the appendix is adequate.

Ruthenium activities are the main contaminants found in the final iodine sample. If a sample is suspected of being contaminated with ruthenium activities, their presence is easily detected by measuring the beta activity in the absence of an absorber and then through $130 \mathrm{mg} / \mathrm{cm} .{ }^{2}$ aluminum absorber. If the ratio of these two activities is less than forty, the sample can be considered to be contaminated and the data on that particular sample discarded.

\section{ACKNOWLEDGEMENT}

The author wishes to acknowledge the competent laboratory assistance of Ruth Fischer. 


\section{APPENDIX}

1. Reagents

I carrier: $11.7 \mathrm{~g}$. NaI dissolved in 1 liter water (standardized as $\mathrm{PdI}$ )

La carrier : $10 \mathrm{mg}$. $\mathrm{La}^{+3} / \mathrm{ml}$. (added as a solution of $\mathrm{La}\left(\mathrm{NO}_{3}\right)_{3} \cdot 6 \mathrm{H}_{2} \mathrm{O}$ in $1 \mathrm{M} \mathrm{HNO}_{3}$ )

Pd carrier: $10 \mathrm{mg}$. $\mathrm{Pd}+2 / \mathrm{ml}$. ladded as a solution of $\mathrm{PdCl}_{2} \cdot 2 \mathrm{H}_{2} \mathrm{O}$ in $1 \mathrm{MHCl}$ )

$\mathrm{HNO}_{3}: 6 \underline{\mathrm{N}}$

$\mathrm{H}_{2} \mathrm{SO}_{4}: 6 \underline{\mathrm{N}}$

$\mathrm{HCl}:$ concentrated and $0.1 \mathrm{~N}$

$\mathrm{NH}_{4} \mathrm{OH}: 6 \underline{\mathrm{M}}$

$\mathrm{Na}_{2} \mathrm{CO}_{3}: 2 \underline{\mathrm{M}}$

$\mathrm{NaNO}_{2}: 1 \underline{\mathrm{M}}$

$\mathrm{NaOC1}: 5$ per cent aqueous solution

$\mathrm{NaHSO}_{3}: 1 \mathrm{M}$

Carbon tetrachloride - reagent grade

\section{Procedure}

Step 1 - Pipet $1.0 \mathrm{ml}$. of the I carrier into a $40 \mathrm{ml}$. conical tipped pyrex glass centrifuge tube and add an aliquot of the sample: add $2 \mathrm{M} \mathrm{Na} \mathrm{NO}_{3}$ until the solution is basic (Note 1), then add $1 \mathrm{ml}$. 5 per cent $\mathrm{NaOCl}$ solution. Heat for approximately two minutes over a gas flame (Note 2).

Step 2 - Add $6 \underline{\mathrm{N}} \mathrm{H}_{2} \mathrm{SO}_{4}$ until solution is acid; add about $1 \mathrm{ml} .1 \mathrm{M}$ $\mathrm{NaHSO}_{3}$ (Note 3 ): add $1 \mathrm{ml}$. La carrier and dilute to $15 \mathrm{ml}$ : add minimum amount of $6 \mathrm{M} \mathrm{NH} \mathrm{NH}_{4} \mathrm{OH}$ necessary to make the solution basic (Note 4). Centrifuge out the La(OH) 3 formed (Note 5).

Step 3 - Decant the supernate from step 2 into a clean $40 \mathrm{ml}$ conical tipped pyrex glass centrifuge tube; add $6 \mathrm{~N} \mathrm{H}_{2} \mathrm{SO}_{4}$ until solution is just acid: add $1 \mathrm{ml}$. La carrier and sufficient $6 \mathrm{M}$ $\mathrm{NH}_{4} \mathrm{OH}$ to make the solution basic (Note 4 ). Centrifuge out the La(OH) formed (Note 5).

Step 4 - Repeat step 3.

Step 5 - Decant the supernate from step 4 into a clean $40 \mathrm{~mL}$. conical tipped pyrex glass centrifuge tube and add $2 \mathrm{ml} .6 \mathrm{~N} \mathrm{HNO}_{3}$; transfer solution to a ruthenium distillation flask which has a slow stream of air passing through it $(1-2$ bubbles/second) and the delivery tip under the surface of $15 \mathrm{ml}$. water 
containing approximately $1 \mathrm{ml} / \mathrm{M} \mathrm{NaHSO}_{3}$ in a $40 \mathrm{ml}$. centrifuge tube; add approximately $1 \mathrm{ml} .1 \mathrm{M} \mathrm{NaNO}$ to the distillation flask (Note 6). Heat the distillation flask with a small gas flame to distill the iodine (Note 7) vapors.

Step 6 - After all the iodine has been distilled, acidify the receiving tube with $3 \mathrm{ml} 6 \mathrm{~N} \mathrm{HNO}_{3}$ and transfer solution to a $100 \mathrm{ml}$. pear-shaped separatory funnel containing $15 \mathrm{ml}$. carbon tetrachloride: add $1 \mathrm{ml}_{2} 2 \mathrm{M} \mathrm{NaNO}_{2}$ and extract the iodine formed into the organic layer (Note 8) by shaking: separate the phases, discarding the aqueous (upper layer).

Step 7 - Transfer the organic phase to a clean separatory funnel: add $15 \mathrm{ml}$. water and $1 \mathrm{ml} .1 \mathrm{MNASO}$ (Note 9); extract iodine into aqueous layer and discard the organic phase (lower layer).

Step 8 - To the aqueous phase add $2 \mathrm{ml} .6 \mathrm{~N} \mathrm{HNO}_{3}$ add $15 \mathrm{ml}$. fresh fresh carbon tetrachloride and $1 \mathrm{ml} .2 \mathrm{M} \mathrm{NaNO}_{2}$; extract iodine into the organic phase by shaking; discard aqueous phase (upper layer).

Step 9 - Repeat step 7, step 8, and step 7 in this order.

Step 10 - Add concentrated HCl to the aqueous from step 9 until solution is approximately $0.1 \mathrm{~N} \mathrm{HCl}$; heat to boiling; add an equal volume of absolute ethanol (Note 10) and $1 \mathrm{ml}$. Pd carrier. Let solution cool to room temperature and centrifuge out $\mathrm{PdI}_{2}$ precipitate. Discard supernate.

Step 11 - Wash precipitate with $10 \mathrm{ml}$. absolute ethanol; centrifuge out precipitate and discard the wash solutions.

Step 12 - Suspend the washed $\mathrm{PdI}_{2}$ in $10 \mathrm{ml}$ a asolute ethanol and filter it onto a weighed disc of Whatman No. 42 filter paper (Note 11).

Step 13 - Dry the precipitate by vacuum desiccation using the following sequence: two minute evacuation, release vacuum, evacuate for approximately 30 seconds, release vacuum, evacuate for 2 minutes, etc. This is repeated until the precipitate has received a total of three two minute evacuations. The sample is exposed to air for approximately 5 minutes to come to moisture equilibrium with the sur m rounding air and is then weighed to determine the chemical yield. 
Step 14 - The sample is mounted and counted (Note 12).

Notes

1. The basicity of the solution is measured with $\mathrm{pH}$ paper after the solution fals to effervesce upon $\mathrm{Na}_{2} \mathrm{CO}_{3}$ addition.

2. The heating is necessary to ensure chemical exchange between carrier and the radioactive lodine present.

3. Sufficient $\mathrm{NaHSO}_{3}$ has been added when the color sequence light yellow to brown to colorless is observed.

4. The presence of excess $\mathrm{NH}_{4} \mathrm{OH}$ can be determined by wet litmus.

5. The $\mathrm{La}(\mathrm{OH})_{3}$ precipitates will contain much of the fission activity in the original sample. Thus, it is advisable to discard the tubes with their solid waste into a dry active waste pot.

6. The $\mathrm{NaNO}_{2}$ oxidizes the iodide ion to elementary iodine. The solution should turn brown.

7. The elementary iodine is distilled with the water vapors. Sufficient heating and distillation should be carried out until the side arm of the flask contains no crystalline iodine deposits. Make sure sufficient $\mathrm{NaHSO}_{3}$ is kept in the receiving flask to reduce the iodine to iodide.

8. The elementary iodine should give the organic phase a violet color.

9. The $\mathrm{NaHSO}_{3}$ reduces the iodine to iodide which is water soluble. This reaction is complete when the organic phase is colorless.

10. The 1 to 1 volume mixture of $0.1 \mathrm{~N} \mathrm{HCl}$ and absolute ethanol is used for the precipitation to avoid peptization of the precipitate in the alcohol washes later on in Step 11.

11. The filter paper used for collecting the washed $P \mathrm{dI}_{2}$ should be pretreated by washing with absolute ethanol and dried as described in Step 13 and weighed before using.

12. The sample should be checked for possible ruthenium contamination. This is done by taking twro counts on the sample, one without an absorber and the other with an approximately $130 \mathrm{mg} / \mathrm{cm}^{2}$ aluminum. The ratio of these two counts should be greater than 40 . If the ratio is less, the sample can be 
assumed to have ruthenium contamination. To prevent contamination of future samples greater care should be exercised in carrying out the carbon tetrachloride extraction, since this is the step which separates the contaminating ruthenium activity from the iodine. 


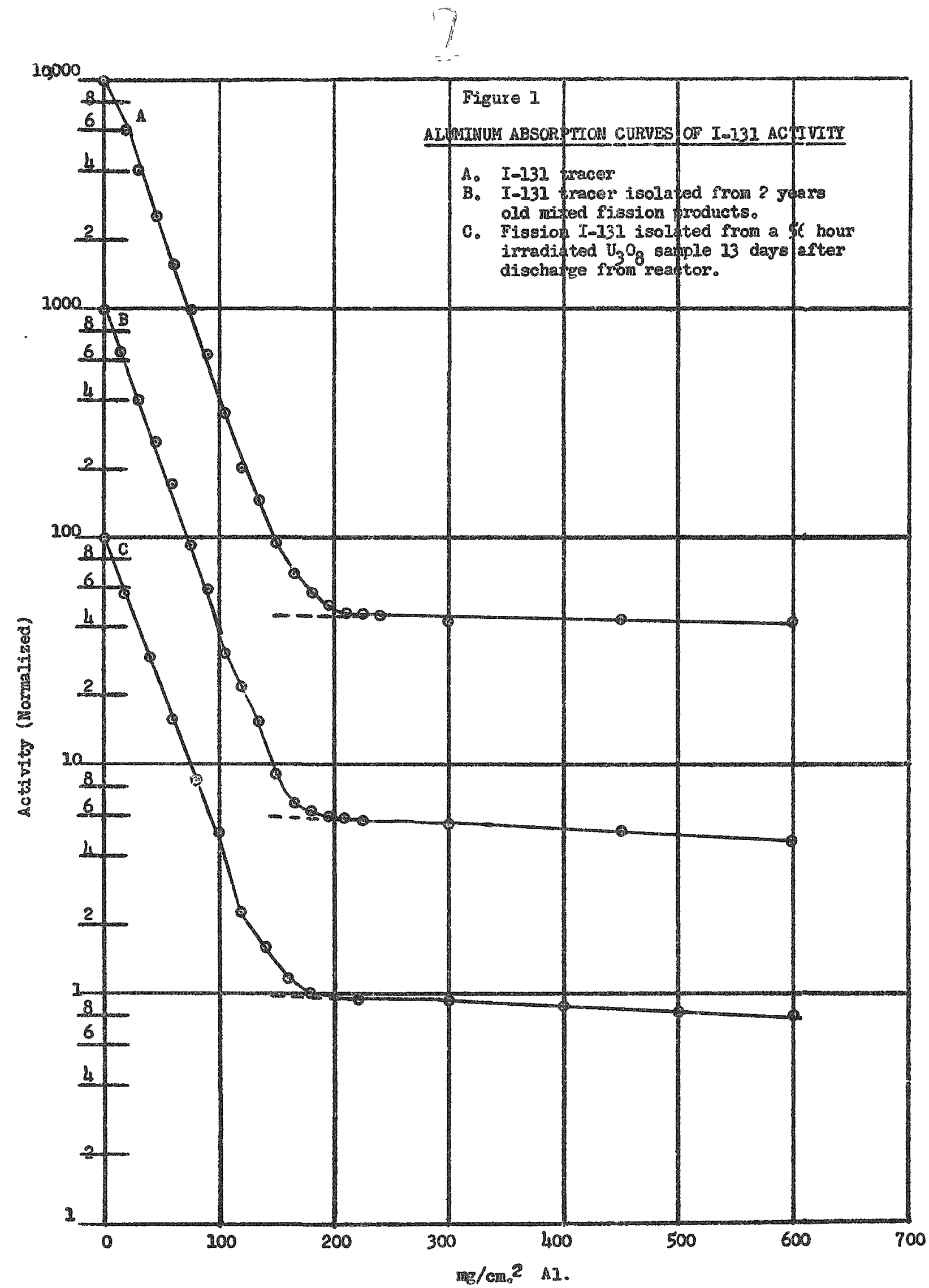




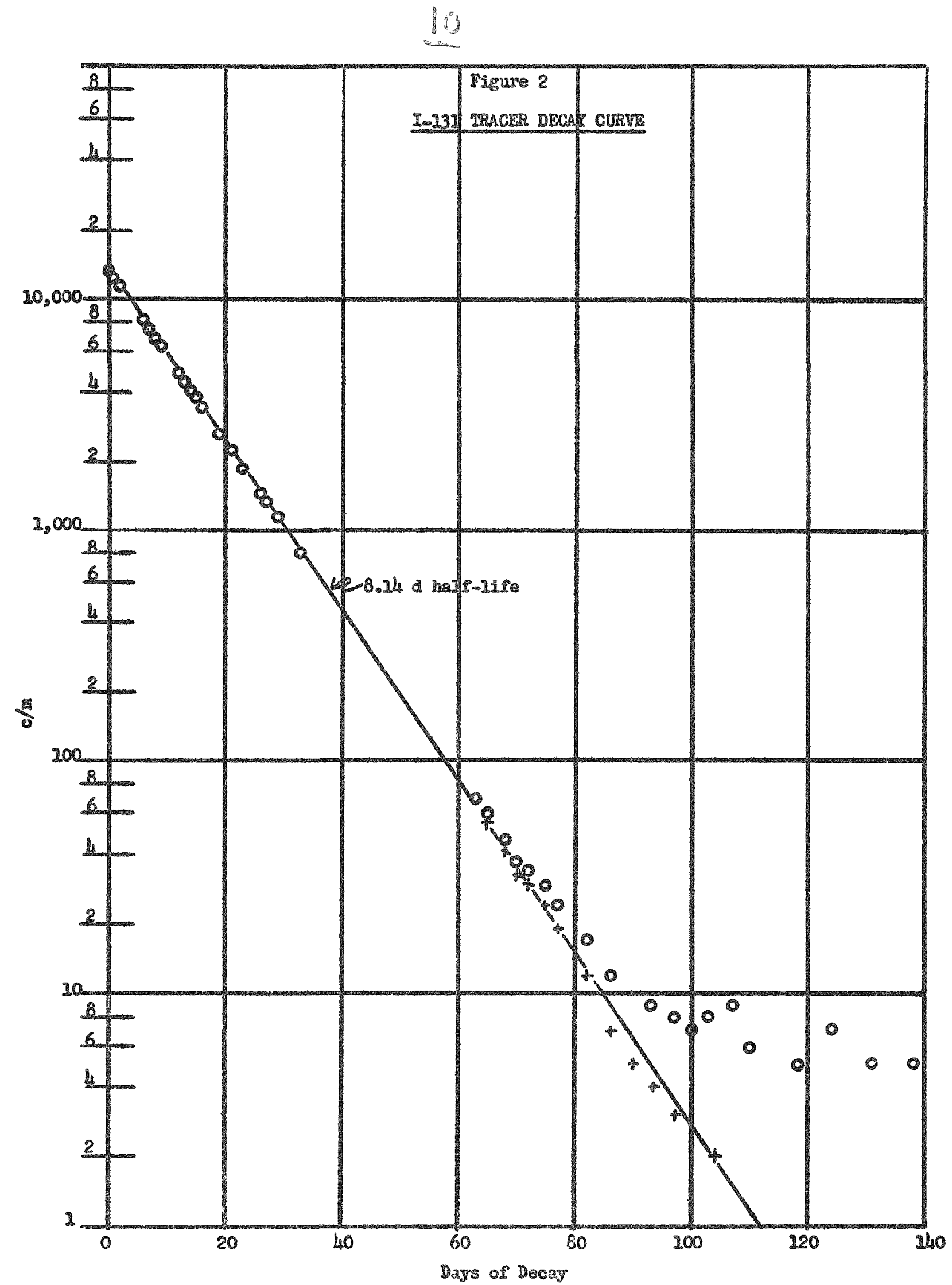




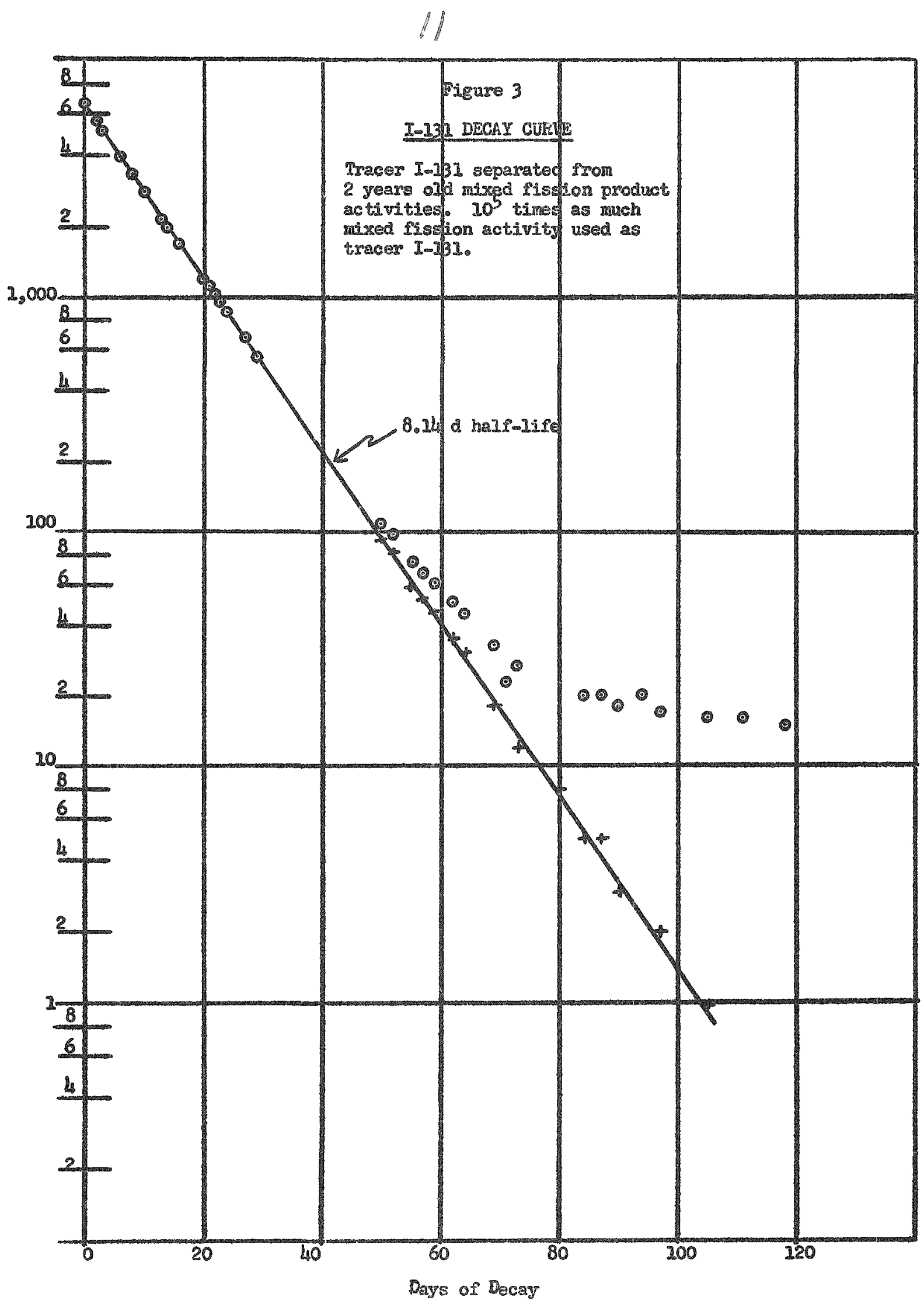




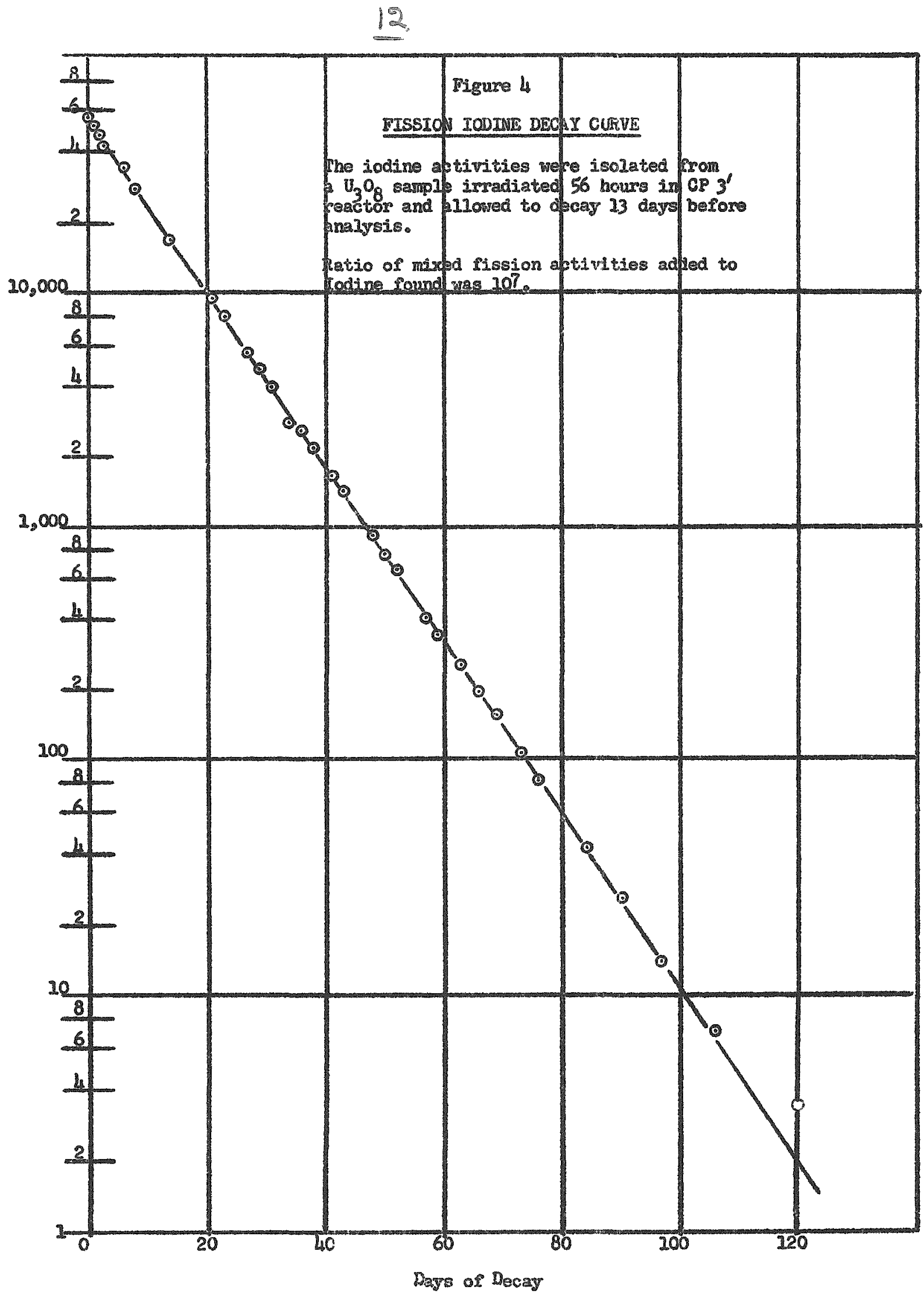

